\title{
Conformer Selection of Protein Ions by Ion Mobility in a Triple Quadrupole Mass Spectrometer*
}

\author{
K. A. Cox, R. K. Julian, Jr., and R. G. Cooks \\ Department of Chemistry, Purdue University, West Lafayette, Indiana, USA \\ R. E. Kaiser, Jr. \\ Lilly Corporate Research, Eli Lilly \& Co., Indianapolis, Indiana, USA
}

Electrospray mass spectra of multiply charged protein molecules show two distinct charge state distributions proposed to correspond to a more highly charged, open conformational form and a lower charged, folded form. Elastic collisions carried out in the radiofrequencyonly collision cell of a triple quadrupole mass spectrometer have dramatic effects on the appearance of the mass spectra. The different cross sectional areas of the conformers allow preferential selection of one charge state distribution over the other on the basis of ion mobility. Preferential selection is dependent on the nature and pressure of the target gas as well as the nature of the protein. In the case of positively charged horse heart apomyoglobin (MW 16,951 da), a high charge state distribution centered around $(\mathrm{M}+20 \mathrm{H})^{20+}$ predominates at low target gas pressures and a second distribution centered around $(M+10 \mathrm{H})^{10+}$ predominates at high target gas pressures. Bimodal distributions are observed at intermediate pressures and, remarkably, charge states between the two distributions are not effectively populated under most of the conditions examined. Hard sphere collision calculations show large differences in collision frequencies and in the corresponding kinetic energy losses for the two conformational states and they demonstrate that the observed charge state selectivity can be explained through elastic collisions. (J Am Sor Mass Spectram 1994, 5, 127-136)

$\mathrm{E}$ lectrospray ionization (ESI) has become a powerful method in the analysis of large, thermally labile compounds $[3,4]$. Ions are generated by passing a liquid through a charged needle. The liquid emerging from the needle acquires a surface charge and rapidly disperses into a fine spray of charged droplets [5-8]. The droplets are then accelerated through an electric potential entering the mass spectrometer via a capillary, and undergoing desolvation in the presence of heated nitrogen drying gas at the capillary interface.

The generation of ionized proteins bearing a large number of charges allows mass spectrometers with relatively low mass-to-charge ratio ranges to be used for biopolymer analysis. Accurate (ca. $0.01 \%$ ) molecular weight determinations for proteins having molecular weights as high as 100,000 da have been achieved [9], protein mixtures have been characterized [10], and

\footnotetext{
* Note: The results reported in this article were obtained concurrently with, but independently of, the work recently reported by Covey and Douglas [1] and Feng and Konishi [2].

Address reprint requests to Prof. R. G. Cooks, Department of Chemistry, Purdue University, West Lafayette, IN 47907.
}

ion-molecule studies on highly charged peptide and protein molecules have also been conducted [11-13].

Given the increasing importance of electrospray experiments, an understanding of the fundamental behavior of highly charged proteins in the gas phase is highly desirable. In one approach, models have been developed to explain the effects of coulombic repulsion on the stability and dissociation of highly charged species [14]. Many studies have also been conducted to determine whether distinct conformational structures present in solution are retained in the gas phase [15-23]. Results show that manipulation of solutionphase conditions such as $\mathrm{pH}$ [17], solvent choice [18], and thermal heating [19-21] does indeed produce noticeable changes in the charge state distributions observed for the protein ions in the gas phase. Hydrogen/deuterium exchange also has been used to effectively monitor conformational changes of proteins in solution [22] and ESI mass spectrometry has proven an effective probe in monitoring the reversibility of heatinduced denaturization of proteins [19]. The correlation between established solution-phase methods for protein structure manipulation and gas-phase charge distribution shifts indicates that some measure, at least, of conformational distinction is retained when protein ions are transferred from solution to the gas phase. 
Sequence information has been obtained on multiply charged protein molecules through tandem (MS/MS and MS') mass spectrometry experiments. In these experiments the accelerated ions collide with a target gas and dissociate into characteristic fragments [24-26]. Increasing the internal energy of the precursor ion through collisional excitation in the source region enhances collision-induced dissociation (CID) efficiencies [27]. However, a different process occurs at extremely low collision energies. Rather than dissociating into sequence-specific fragments, low energy multiply charged ions have been reported to undergo proton transfer reactions with appropriate targets, resulting in a shift in the charge state distribution to lower charge (higher mass-to-charge ratio') values [11-13]. For example, apomyoglobin gives multiply charged molecular ions of the type $(\mathrm{M}+\mathrm{nH})^{\mathrm{n}+}$ where $n$ is centered at 18 charges, when ionized by ESI in a Paul ion trap [12]. This distribution shifts to lower charge states when collisions with dimethylamine are permitted, centering around 14 charges under typical conditions. In addition, some adduct formation accompanies the loss of protons. More basic target gases shift the distribution to even lower charge states.

Ikonomou and Kebarle [11] observed an even larger shift in the cytochrome $c$ charge state distribution and attributed this to collisions in the desolvation region prior to the capillary inlet to the mass spectrometer. The main distribution of ions was centered around the $(\mathrm{M}+14 \mathrm{H})^{14+}$ ion, but a second distribution began at $(\mathrm{M}+11 \mathrm{H})^{11+}$ and extended to lower charge values. Addition of tributylamine into the system prior to the capillary inlet resulted in an even larger shift to lower charge states. Unlike the MS/MS experiments of McLuckey et al. [12], which were performed on isolated ions of a single mass-to-charge ratio value, Ikonomou and Kebarle [11] allowed the entire molecular ion envelope to be subjected to collisions with the base. The result was the appearance of a new charge state envelope with an abundance approaching that of the original distribution.

The experiments reported here are complementary to the results of the ion-molecule reactions described above, and reveal interesting evidence which suggests that the collision phenomenon at low energies is more complex than initially assumed. In particular, it is shown that elastic collisions play a role which can be even more significant than that of the reactive collisions described by McLuckey et al. [12] and by Ikonomou and Kebarle [11]. In this article, we report the results of collisions of multiply charged protein ions with argon and other target gases in the radio frequency (RF)-only octopole of a modified triple quadrupole mass spectrometer at low energies. An apparent charge state shift is observed, with a lower charge state distribution becoming more abundant with increasing target gas pressure. Apparently similar phenomena were observed by Loo et al. [28] when collisions took place in the source of the mass spectrometer. As expected, the process is more dramatic when collisions take place in the longer collision cell. It seems that the same phenomenon was also observed by Feng and Konishi [29], who attributed the preferential loss of the denatured state of papain over the native state upon addition of collision gas to "fragmentation or scattering." The present examination of the phenomenon reveals that both charge state distributions are often present initially in the source, but that their relative abundances observed at the detector can be altered by changing the collision conditions. The higher charge state ions are removed upon introduction of an inert collision gas but, when an appropriately high accelerating potential is applied to the third quadrupole, the original charge state distribution is reestablished. Hard sphere collision theory [30, 31] predicts a direct dependence of the collision frequency on the size of the ion. Thus, ions of two different sizes (i.e., different conformers) are expected to exhibit different behavior in the collision cell. Larger ions (higher charge states) will have higher collision frequencies and correspondingly will lose more kinetic energy than the lower charge state (folded) ions. In analyzing these results, the effects of differences in kinetic energy of the precursor ions are also considered.

\section{Experimental}

ESI was performed by using a Finnigan (San Jose, CA) TSQ700 triple quadrupole mass spectrometer fitted with a Finnigan ESI source. In this instrument, the second stage analyzer is not a quadrupole, but an octopole designated as $\mathrm{Q}_{2}$. In all of the experiments described here, the octopole was operated in the RFonly mode and thus was used only as a collision cell. A Harvard Apparatus (South Natick, MA) syringe pumping system was used to infuse the protein samples directly into the ESI source at flow rates ranging from $0.75 \mu \mathrm{L} / \mathrm{min}$ (positive ion experiments) to 3 $\mu \mathrm{L} / \mathrm{min}$ (negative ion experiments). Voltages of -3700 to $-4200 \mathrm{~V}$ (for positive ions) and $+3000 \mathrm{~V}$ (for negative ions) were maintained on the ESI electrode for optimum multiple charging of the peptide. The heater temperature for the $\mathrm{N}_{2}$ drying gas was maintained at $250^{\circ} \mathrm{C}$ for all experiments. The $\mathrm{N}_{2}$ gas temperature exiting the capillary was actually much lower (estimated at approximately $75^{\circ} \mathrm{C}$ ). The mass spectrometer was calibrated with horse heart apomyoglobin (Sigma Chemical Co., St. Louis, MO) for massto-charge ratio values up to $1693 \mathrm{da} /$ charge and trypsinogen for mass-to-charge ratin values up to 3500 $\mathrm{da} /$ charge. In the positive ion experiments, quadrupole potentials were set relative to the grounded source at $-10 \mathrm{~V}$ for Q1 and for the RF-only octopole, and at -5 $V$ for the third quadrupole unless otherwise stated. Negative ion experiments were performed with potentials of +10 volts on $\mathrm{Q} 1$ and on the RF-only octopole and +5 volts on the third quadrupole. All potentials are relative to the grounded ion source. The resolution was typically set much lower for negative ion experiments due to the poorer performance in this mode. 
Scans were averaged for 1 minute to obtain the recorded spectra. An algorithm supplied by Finnigan was used to transform the mass-to-charge spectra to mass spectra. Mass spectral data were taken by passing ions of all mass-to-charge ratios through the first two quadrupoles and scanning the third quadrupole (Q3 MS). Target gases (argon or sulfur hexafluoride) were added to the RF-only octopole at nominal pressures ranging from 0.5 to 2 mtorr. Samples were obtained commercially from Sigma Chemical and were used without further purification. In general, samples used for positive ion experiments were dissolved in $50: 50 \mathrm{H}_{2} \mathrm{O}: \mathrm{CH}_{3} \mathrm{CN}, 5 \%$ acetic acid, at picomole/per microliter concentrations. Samples used for negative ion experiments were dissolved in 50:50 $\mathrm{H}_{2} \mathrm{O}: \mathrm{CH}_{3} \mathrm{CN}, 1 \% \mathrm{NH}_{4} \mathrm{OH}$, at picomole/per microliter concentrations. In the $\mathrm{pH}$ dependence studies, apomyoglobin samples were dissolved in 50:50 $\mathrm{CH}_{3} \mathrm{CN}: \mathrm{H}_{2} \mathrm{O}$ and diluted in varying amounts of formic acid, acetic acid, or ammonium hydroxide to achieve the desired $\mathrm{pH}$ values.

\section{Results}

A summary of all the proteins examined is given in Table 1, along with the molecular weights, number of amino acids, and the most abundant peaks of the charge state distributions observed in the absence and presence of collision gas. Collision gas (either argon or $\mathrm{SF}_{6}$ ) was added at pressures sufficient to induce the maximum charge state distribution shift for each protein examined. Note (from Figures 1 and 2) that the amount of collision gas added does not cause changes in the width of the two charge state distributions observed, only in their abundances relative to each other. Likewise, the same distributions were observed regardless of whether the collision gas was argon or $\mathrm{SF}_{6}$.

In each of the proteins examined, except for the negative ion spectra of somatotropin, both charge state distributions are observed, although at different abundances. When the high charge state distribution is preferentially depleted in the presence of collision gas, an overall loss in sensitivity is observed. In general, two distinct distributions are observed and charge states between the two distributions are not effectively populated at any target gas pressure. The separation between the two distributions appears to be compound and charge state dependent. In the absence of collision gas, the high charge state distribution always dominates, but the abundance of the lower charge state distribution varies with the nature of the protein analyzed.

The experiments involving negative ions represent an alternative way of examining the conformational

Table 1. Most probable charge states of the proteins studied

\begin{tabular}{|c|c|c|c|c|}
\hline Protein & $\begin{array}{c}\text { Molecular } \\
\text { weight }\end{array}$ & $\begin{array}{l}\text { Number of } \\
\text { amino acids }\end{array}$ & $\begin{array}{c}\text { Initial } \\
\text { charge }^{\mathrm{a}}\end{array}$ & $\begin{array}{c}\text { Final } \\
\text { charge }\end{array}$ \\
\hline $\begin{array}{l}\text { Cytochrome } c \\
\text { (bovine heart) }\end{array}$ & 12,232 & 124 & +16 & +10 \\
\hline $\begin{array}{l}\text { Lysozyme } \\
\text { (chicken egg white) }\end{array}$ & 14,315 & 129 & +12 & +8 \\
\hline $\begin{array}{r}\alpha \text {-Lactalbumen } \\
\text { (bovine milk) }\end{array}$ & 14,187 & 123 & +11 & +8 \\
\hline $\begin{array}{l}\text { Apomyoglobin } \\
\text { (equine) }\end{array}$ & 16.951 & 153 & +20 & +9 \\
\hline $\begin{array}{l}\text { Apomyoglobin } \\
\text { (equinel }\end{array}$ & 16,951 & 153 & -17 & -6 \\
\hline $\begin{array}{l}\text { Met-proglucagon } \\
\text { (bovine, } \\
\text { recombinant) }\end{array}$ & 18,789 & 161 & +21 & +9 \\
\hline $\begin{array}{l}\text { Met-proglucagon } \\
\text { (bovine, } \\
\text { recombinant) }\end{array}$ & 18.789 & 161 & -17 & -8 \\
\hline $\begin{array}{l}\text { Somatotropin } \\
\text { (human, } \\
\text { recombinant) }\end{array}$ & 22,125 & 191 & +16 & +10 \\
\hline $\begin{array}{l}\text { Somatotropin } \\
\text { (human, } \\
\text { recombinant) }\end{array}$ & 22.125 & 191 & -9 & -8 \\
\hline $\begin{array}{l}\text { Trypsinogen } \\
\text { (bovine) }\end{array}$ & 23,981 & 229 & +14 & +11 \\
\hline
\end{tabular}

Without collision gas, center of charge state distribution

bith added collision gas, center of charge state distribution. 


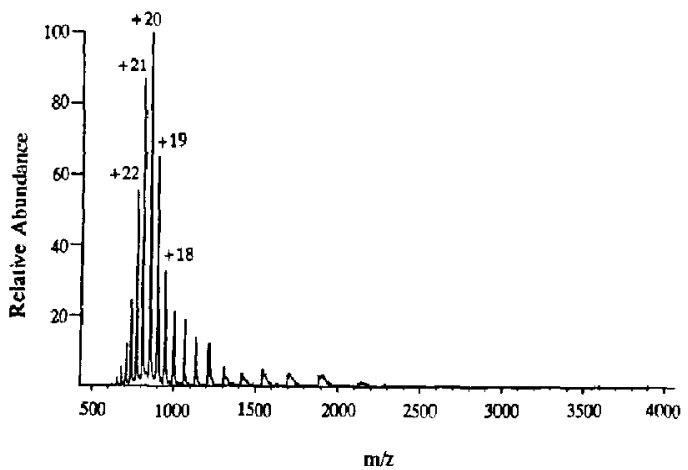

(a)

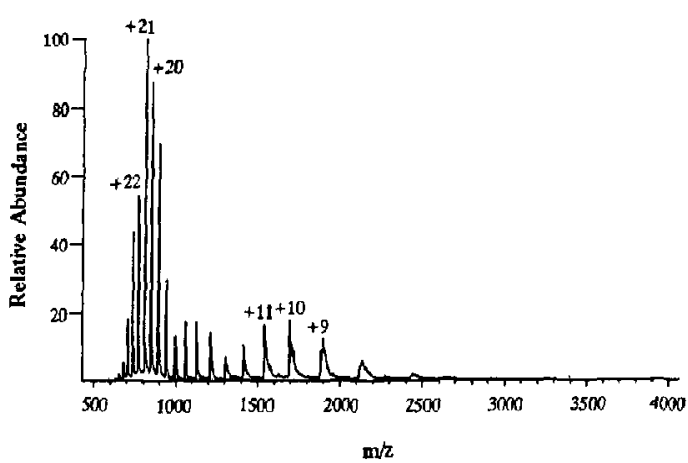

(b)

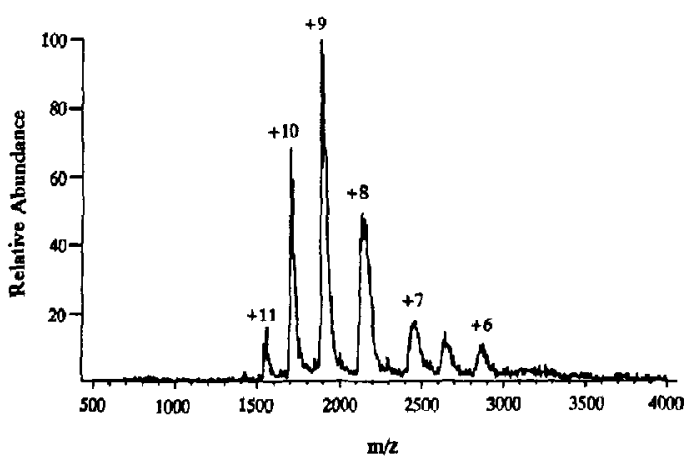

(c)

Figure 1. Posilive ion electrospray mass spectra of aponyoglobin recorded by scanning $Q 3$ of a triple quadrupole mass spectrometer with (a) no collision gas, (b) 0.5 mtorr argon, and (c) 2 mtorr argon added to Q2.

states of proteins by employing different solution conditions. The two distributions should be equally readily observed in the positive and negative charge states only if (1) the charging process itself causes no change in the conformation of the molecules and (2) the relative ease of ionization of the two forms are equal in the positive and negative ion modes. We interpret the

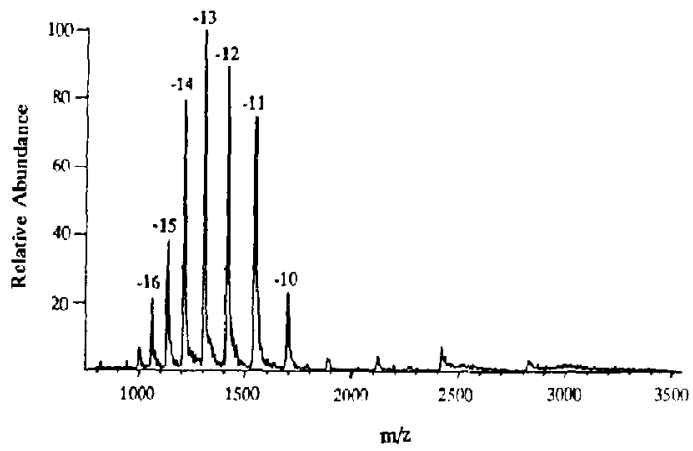

(a)

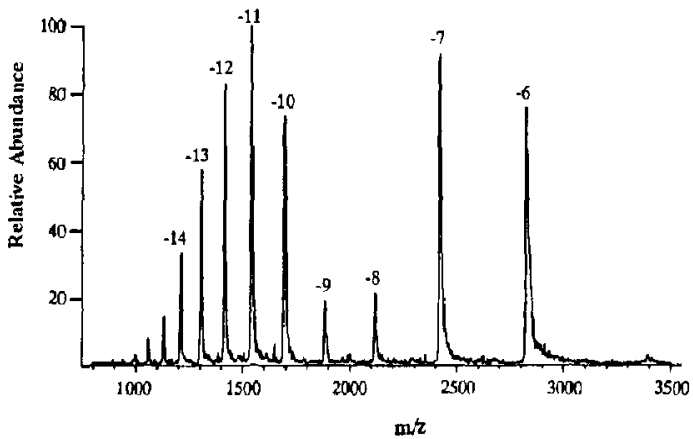

(b)

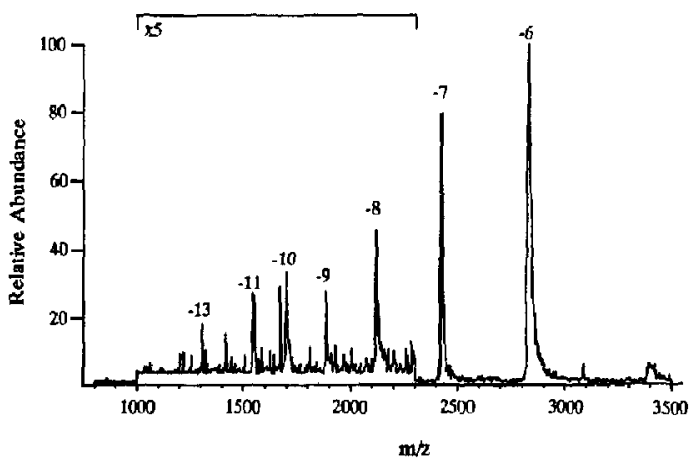

(c)

Figure 2. Negative ion electrospray mass spectra of apomyoglobin recorded by scanning Q3 of a triple quadrupole mass spectrometer with (a) no collision gas, (b) 1.0 mtorr argon, and (c) 2.1 mtorr argon added to $\mathrm{Q} 2$

differences in the positive and negative ion distributions as an indication that one or the other of these conditions is not completely satisfied. The negative ion mass spectrum of bovine met-proglucagon shows the presence of the lower charge state distribution even when collision gas is not deliberately added, while the negative ion mass spectrum of apomyoglobin shows only small abundances of the lower charge state distribution until at least 1 mtorr argon collision gas is 
added. This is most likely due to tendencies of different proteins to exist in a particular conformational state under the experimental solution phase conditions used and this is confirmed in the $\mathrm{pH}$ study on apomyoglobin described below.

The charge shift phenomenon in the negative ion spectra of somatotropin is small, showing a charge state shift of only one upon the addition of collision gas. Clearly, this shift is too small to be assigned with confidence to the preferential selection of a different conformational state. This result is not surprising because somatotropin is one of the larger molecular weight proteins studied, and it incorporates only a small number of negative charges. It is possible that only one conformational state exists for this compound under the solution phase conditions $\left(1 \% \mathrm{NH}_{4} \mathrm{OH}\right)$ necessary to generate negative ions.

In the case of positively charged ions from horse heart apomyoglobin (MW 16,951) a charge state distribution centered around the $(\mathrm{M}+20 \mathrm{H})^{20+}$ ion predominates in the absence of collision gas (Figure 1a). As argon is introduced into the collision cell, the intensity of the ions making up this initial distribution decreases and a second group of molecular ions centered around $\mathrm{n}=+10(\mathrm{M}+10 \mathrm{H})^{10+}$ appears more pronounced (Figure 1b). As the gas pressure is raised further (Figure 1c), the initial charge state distribution is completely removed, leaving only the lower charge state distribution.

A similar phenomenon is observed in the analysis of negatively charged apomyoglobin. With no collision gas present, the apomyoglobin negative ion charge state distribution is centered around $\mathbf{n}=-13, m / z$ $1303(\mathrm{M}-13 \mathrm{H})^{13-}$ (Figure 2a). Note the broadness of the peaks and the poorer signal-tu-noise ratios as conpared to the positive ion spectra. When a small amount of argon is introduced ( $0.5 \mathrm{mtorr})$, a second distribution appears with much lower charge states centered around $\mathbf{n}=-7, m / z 2421(\mathrm{M}-7 \mathrm{H})^{7-}$. At higher collision gas pressures (Figure $2 \mathrm{~b}$ ) both distributions have comparable abundances, and at a pressure of $2.1 \mathrm{mtorr}$ argon, the $(\mathrm{M}-7 \mathrm{H})^{7-}$ and $(\mathrm{M}-6 \mathrm{H})^{6-}$ ions predominate, while the original envelope makes only a small contribution to the total ion current. In both positive and negative ion experiments, when argon was replaced with the much larger collision gas, $\mathrm{SF}_{6}$, the same selection phenomenon was observed, however, lower target gas pressures were required.

Remarkably, the higher charge state distribution can be regained by simply manipulating the offset potential of the third quadrupole relative to the collision cell. Figure 3a shows the spectrum of positively charged apomyoglobin when no collision gas is added to $\mathrm{Q} 2$ and $\mathrm{Q3}$ is held at an offset of $-5 \mathrm{~V}$ relative to the collision region which is held at a potential of -10 $\mathrm{V}$ relative to the grounded ion source. In the presence of $1 \mathrm{mtorr}$ argon (Figure $3 \mathrm{~b}$ ), the high charge state distribution has nearly disappeared. As the potential of Q3 is decreased relative to Q2, the ions experience an

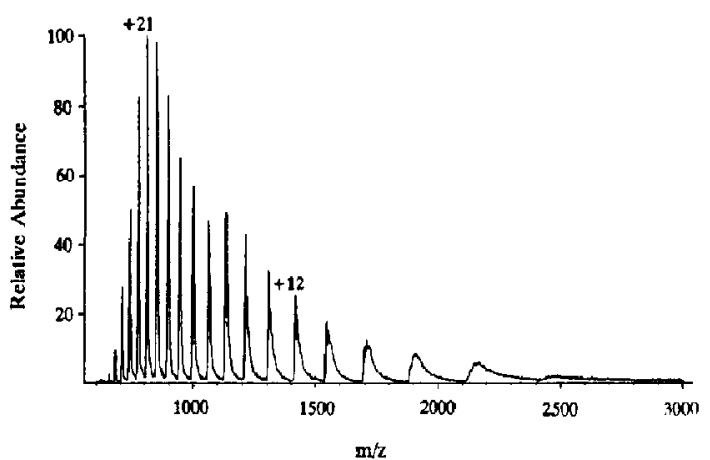

(a)

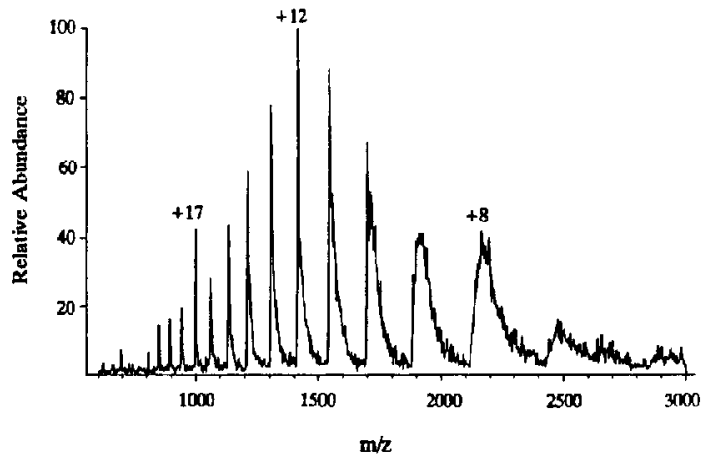

(b)

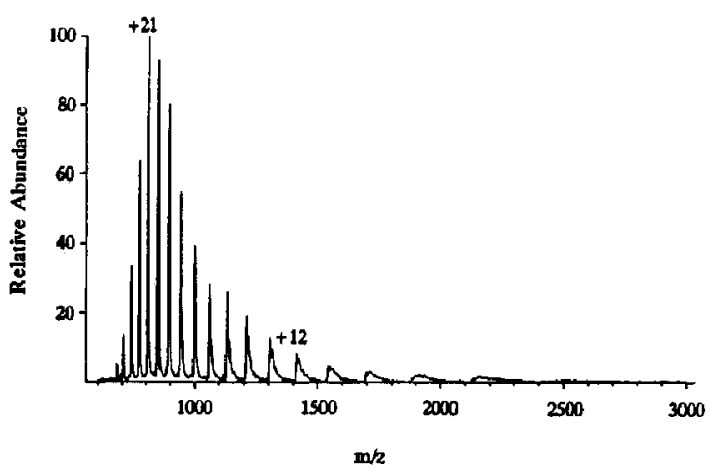

(c)

Figure 3. Positive ion electrospray mass spectra of apomyoglobin recorded by scanning $Q 3$ of a triple quadrupole mass spectrometer at (a) a $Q 3$ potential of $-5 \mathrm{~V}$ and no collision gas in $\mathrm{Q2}$, (b) a $\mathrm{Q3}$ potential of $-5 \mathrm{~V}$ and 1 mtorr argon added to $\mathrm{Q2}$, and (c) a $Q 3$ potential of $-20 \mathrm{~V}$ and 1 mtorr argon added to $Q 2$.

increased accelerating potential and the original high charge state distribution reappears (Figure 3c). These experiments were performed on an apomyoglobin sample containing $10 \%$ acetic acid. Higher resolution experiments performed under these conditions showed adducts greater in mass by $59 \mathrm{da}$, indicating a contribution to the broadness of these peaks due to acetate adducts. 
Table 2, Effect of $\mathrm{pH}$ on most probable charge state of apomyoglobin

\begin{tabular}{clccc}
\hline $\mathrm{pH}$ & $\begin{array}{c}\% \text { acid } / \text { base } \\
\text { in } \mathrm{CH}_{3} \mathrm{CN}: \mathrm{H}_{2} \mathrm{O}\end{array}$ & $\begin{array}{c}\text { Initial } \\
\text { Charge }^{\mathrm{B}}\end{array}$ & $\begin{array}{c}\text { Final } \\
\text { Chargeb }\end{array}$ & $\begin{array}{c}\text { Sensitivity } \\
\text { Loss }\end{array}$ \\
\hline \hline 1 & $50 \%$ formic & +20 & +10 & 30 \\
3 & $2 \%$ acetic & +20 & +13 & 30 \\
3 & $10 \%$ acetic & +21 & +14 & 20 \\
5 & $\mathrm{CH}_{3} \mathrm{CN}: \mathrm{H}_{2} \mathrm{O}$ & +20 & +13 & 20 \\
7 & $0.04 \% \mathrm{NH}_{4} \mathrm{OH}$ & +17 & +12 & 15 \\
$10^{\mathrm{c}}$ & $1 \% \mathrm{NH}_{4} \mathrm{OH}$ & +14 & +9 & 2 \\
$11^{\circ}$ & $50 \% \mathrm{NH}_{4} \mathrm{OH}$ & +15 & +9 & 6 \\
\hline
\end{tabular}

Without collision gas, center of charge state distribution.

Dith 1.0 mtorr of argon, center of charge state distribution.

c Two distributions observed initially.

When the Q3 offset potential is adjusted so that it is a few volts above the source potential, all ions are strongly decelerated. In principle, no ions of any charge state should be transmitted through Q3, but in practice potentials a few volts above ground are needed to completely retard ion beams in quadrupole mass spectrometers. Even in the absence of added collision gas (at a nominal manifold pressure on the order of $10^{-5}$ torr), the low charge state distribution can be preferentially selected when the potential of the third quadrupole is appropriately chosen. Figure 4 shows the positive ion mass spectra of apomyoglobin at two offset voltages; $-8 \mathrm{~V}$ and $+4 \mathrm{~V}$ in experiments in which Q1 is at $-10 \mathrm{~V}$ and $\mathrm{Q} 2$ is at $-5 \mathrm{~V}$. Note that the higher charge states, which predominate at $-8 \mathrm{~V}$, are virtually eliminated at $+4 \mathrm{~V}$. Thus, even a small amount of collision gas can cause shifts in the relative abundances of the two populations of ions which have different collision cross sections, provided the retarding potential is adjusted so that all ions are decelerated almost to the point of complete retardation. The spectra shown in Figure 4 were taken under slightly different solution phase conditions than those in Figure 1 (i.e., different $\mathrm{pH}$ ). This accounts for the observation of slightly different initial charge state profiles observed in the two figures.

Attempts to monitor the changes in conformational states in the gas phase through manipulation of the solution phase conditions have been extensively studied [17-19] and changes in the solution phase conditions have been interpreted as a means of controlling conformational states. One such experiment was attempted here. The $\mathrm{pH}$ of the solution was varied from $\mathrm{pH}=1$ to $\mathrm{pH}=11$ prior to ion injection into the mass spectrometer and the results are summarized in Table 2 . The charge states reported are for the base peaks in the predominant distributions in the absence of collision gas (initial charge) and in the presence of $1 \mathrm{mtorr}$ argon (final charge). As expected, at low $\mathrm{pH}$, the high charge state species predominates and it is removed when collision gas is introduced into the RF-only octopole (see Figure 5a and $b$ ). The original distribution can be regained by increasing the extraction potential on Q3. At high $\mathrm{pH}$ values, two charge state distributions are observed in similar abundance in the absence of collision gas. When collision gas is added, the higher charge state distribution decreases dramatically in intensity while the lower charge state distribution remains relatively unaffected (Figure $5 c$ and d). This is reflected in the sensitivity losses.

In this study, sensitivity loss is calculated as the loss of signal intensity of the base peak in the spectrum upon addition of 1 mtorr argon. Thus, at low $\mathrm{pH}$, where the high charge state distribution dominates, a large sensitivity loss is observed due to the large

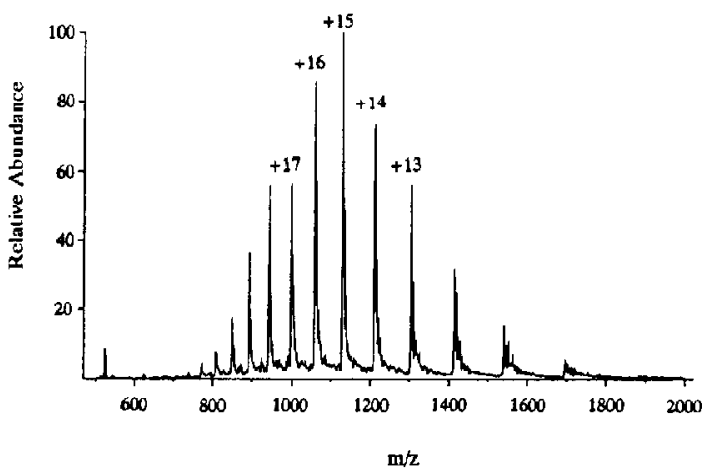

(a)

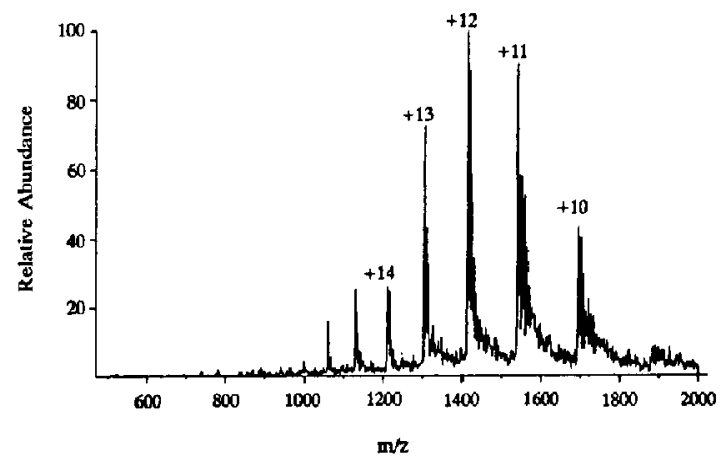

(b)

Figure 4. Positive ion electrospray mass spectra of apomyoglobin recorded by scanning $Q 3$ of a triple quadrupole mass spectrometer in the absence of collision gas with a $Q 3$ offset potential of (a) $-8 \mathrm{~V}$ and (b) $+5 \mathrm{~V}$. 


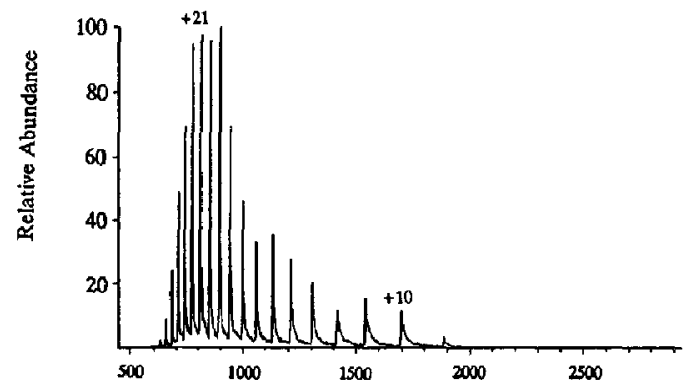

(a)

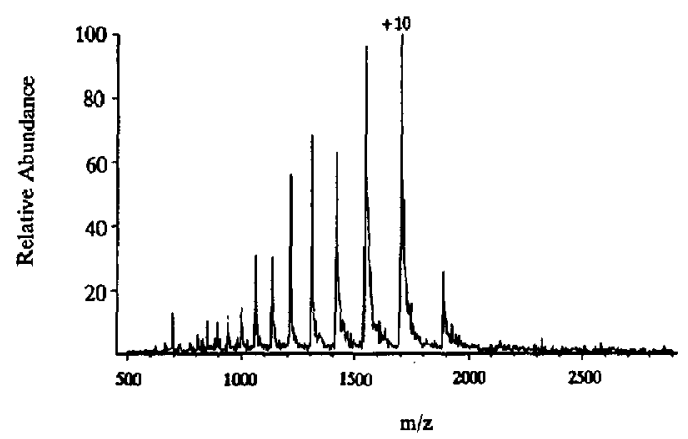

(b)

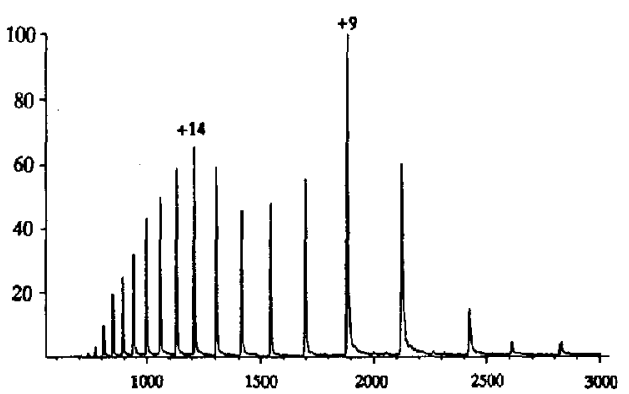

(c)

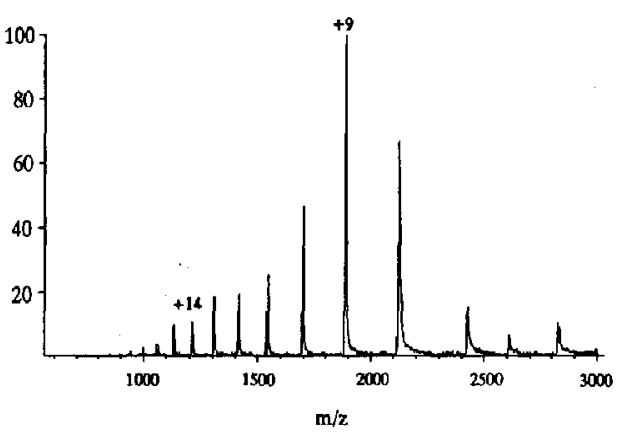

(d)

Figure 5. Positive ion electrospray mass spectra of apomyoglobin recorded at different solution phase $\mathrm{pH}$ values: (a) $\mathrm{pH} \mathrm{1;} \mathrm{no} \mathrm{collision} \mathrm{gas,} \mathrm{(b)} \mathrm{pH} 1 ; 1$ mtorr argon collision gas, (c) $\mathrm{pH} \mathrm{10}$; no collision gas, and (d) $\mathrm{pH} 10 ; 1$ mtorr argon collision gas.

number of collisions these larger ions experience, while a small sensitivity loss is observed at high $\mathrm{pH}$ when the folded state ions dominate, as they are relativeiy unaffected by the presence of the collision gas. Not surprisingly, the base peaks in the distributions vary with $\mathrm{pH}$, that is, the base peak in the high charge state distribution at $\mathrm{pH} 1$ is $m / z 848\left[(\mathrm{M}+20 \mathrm{H})^{20+}\right]$, while at $\mathrm{pH} 11$, the high charge state distribution is centered around $m / z 1131\left[(\mathrm{M}+15 \mathrm{H})^{15+}\right]$.

\section{Discussion}

The presence of bimodal charge state distributions in the ESI mass spectra of proteins has been attributed to the presence of two conformers; a tightly folded statc and a more open form [17-19]. Preferential formation of ions in one state over the other has been achieved by manipulation of source temperature, solvent composition, and $\mathrm{pH}$. If ions of two different conformational forms are generated in the gas phase, then their different physical properties (cross sectional area and charge state) should affect their behavior in the collision region. High energy collisions result in dissociation into sequence-specific fragments, but low energy collisions with nonreactive target gases have not been investigated in detail.

The results presented here are not due to charge changing collisions or collisional dissociation. No change in mass is observed between the high charge state distribution and the low charge state distribution due to the loss (or gain) of protons or other charged species. MS/MS experiments in which an isolated mass-to-charge ion is passed through the collision cell at these low energies show no fragment ions. These ions are not undergoing chemical changes upon passage through the mass spectrometer. The different $\mathrm{m} / \mathrm{z}$ ions are present upon introduction to the mass spectrometer, and manipulation of experimental conditions selects one form over another through the medium of elastic (or quasielastic*) collisions. Nor are the effects simply a consequence of the higher kinetic energies acquired when ions of higher charge state are accelerated through a fixed potential. Such an effect would lead to the opposite behavior upon collision gas introduction to that observed.

Intuitively, a larger ion will undergo many more collisions than a smaller ion traversing the same path. Thus, the larger ion will lose more kinetic energy than the smaller ion and, with sufficient energy loss, will

\footnotetext{
*Quasielastic collisions are collisions which, although not perfectly elastic, do not transfer enough internal energy to induce ion dissociation. Quasielastic collisions result in kinetic energy loss without change in ion mass or charge and are thus indistinguishable from elastic collisions in these experiments.
} 
reach a point at which it is unable to exit the second quadrupole. However, if an additional accelerating potential is applied to the collision cell, these scattered ions may be extracted from the collision cell and detected. This argument is in agreement with the experimental results observed for both positive and negative ions. Calculations of relative collision frequencies and energy losses for ions of different cross sections (see below) support this proposal.

The hard sphere collision model $[30,31]$, used in ion mobility spectrometry calculations, provides the fundamental relationship between ion mobility and collision frequency. Ion mobility spectrometry has recently proved useful in the distinction of carbon cluster isomers $[32,33]$. Some modifications to this model were necessary in describing the experiments in this study, because the multiply charged protein ions move through a region largely free of a potential gradient along the direction of ion motion. To qualitatively illustrate relative differences between protein ions of two different sizes and charge states, rough estimates are used for the diameters of the two conformers. Macfarlane [34] gives the gas-phase diameter of insulin (MW $5804 \mathrm{da}$ ) as a few nanometers and Covey and Douglas [1] report values of $3020 \AA^{2}$ and $5040 \AA^{2}$ for the cross sectional areas of the +11 and +21 charge states of myoglobin, respectively, in which collision cross sections were calculated on the basis of stopping curves. Thus, for illustrative purposes only, the diameters of the folded and open protein conformers were chosen as $50 \AA$ and $100 \AA$, respectively. Note, however, that the calculations of Covey and Douglas are based on the presence of only one conformational form with a distribution of charge states. The present work, on the other hand, identifies two distinct conformational states in the gas phase, each with its own distribution of charges. Thus, the +10 charge state of the native form of a protein is not expected to have the same collision cross section as the +10 charge state of the denatured form.

To apply the hard sphere collision model to elastic collisions, a number of assumptions were made. First, the amount of energy lost is assumed to be directly related to the number of collisions. The amount of energy lost per collision is assumed to be the same for all ions. The initial charge state is assumed to be made up of two distributions of charge states. In the case of apomyoglobin, one is centered around $m / z 848$ (charge $=+20$ ) and the other centered around $\mathrm{m} / \mathrm{z}$ 1696 (charge -+10 ).

In the hard sphere collision model, used in ion mobility spectrometry $[30,31]$, the collision frequency, $\eta$, can be represented by

$$
\eta=\pi N D^{2} v_{0}
$$

where $N$ is the number density of the target gas, and was calculated for 1 mtorr collision gas pressure, $D$ is the diameter of the ion-target complex which is approximately equal to the ion diameter when the size of the ion is much larger than the size of the target, and $v_{o}$ is the velocity of the ion (target velocity is assumed to be negligible).

For the apomyoglobin case, when the accelerating potential is $10 \mathrm{~V}$ and hence when initial velocities of the two conformers (considering also their different charge states) are $v_{\mathrm{oh}}=1500 \mathrm{~m} / \mathrm{s}$ and $v_{\mathrm{ol}}=1100 \mathrm{~m} / \mathrm{s}$, the ratio of the collision frequencies of the two conformers $v_{\mathrm{h}} / v_{1}=5.5$, where $\mathrm{h}$ denotes the high charge (low mass-to-charge ratio) conformer and 1 denotes the low charge (high mass-to-charge ratio) conformer. This quantifies the expected enhancement in the collision frequency of the high charge state conformer. When the collision frequency factor is incorporated into the velocity calculations, and assuming a probability factor (I) (chance of a head-on elastic collision) of 0.1 , the final velocities become $v_{\mathrm{h}}=796 \mathrm{~m} / \mathrm{s}$ and $v_{1}=901 \mathrm{~m} / \mathrm{s}$, a remarkable reversal of the velocities prior to collision. Final kinetic energies calculated from these velocities are $\mathrm{KE}_{\mathrm{h}}=56 \mathrm{eV}(2.8 \mathrm{~V} \times 20$ charges $)$ and $\mathrm{KE}_{1}=71 \mathrm{eV}(7.1 \mathrm{~V} \times 10$ charges $)$. The calculated energies $(\mathrm{eV})$ of the two different conformers after collisions are sufficiently different to prevent the high charge state from leaving $\mathrm{Q} 2$ when $\mathrm{Q} 3$ is held at the normal value of $-5 \mathrm{~V}$ relative to the ion source, while the low charge state still has sufficient energy to reach $\mathrm{Q} 3$ and be detected. (The barrier is $5 \times 20=100 \mathrm{eV}$ for the high charge state and $5 \times 10=50 \mathrm{eV}$ for the low charge state.) Clearly, the magnitude of the extraction potential applied to $\mathrm{Q} 3$ will affect the relative abundances of ions in the two distributions. We are primarily interested in the difference in behavior between the two conformers. The calculations and experiments show also that the effects are more dramatic when the Q3 offset is made more positive (to retard positive ions) or when a much larger target gas $\left(\mathrm{SF}_{6}\right)$ is used as the target gas. In the latter case $v_{\mathrm{h}}=357 \mathrm{~m} / \mathrm{s}, \mathrm{KE}_{\mathrm{h}}=$ $11.2 \mathrm{eV}\left(0.56 \mathrm{~V} \times 20\right.$ charges); $v_{1}=610 \mathrm{~m} / \mathrm{s}, \mathrm{KE}_{1}=$ $32.7 \mathrm{eV}(3.27 \mathrm{~V} \times 10$ charges $)$. Thus, $1 \mathrm{mtor} \mathrm{SF}_{6}$ is sufficient to trap both charge state distributions, whereas 1 mtorr Ar was only able to trap the higher charge state distribution.

Also, note that no consideration is taken of the effects of scattering. It is probable that many ions scatter upon collision with the target and this could also contribute to their observed loss. However, the experiment is done in the strong focusing field of the RF-only octopole, and the magnitude of this term is not known. Nevertheless, the higher charge state (larger size) conformer undergoes many more collisions, increasing its probability of scattering, and further supporting the observed results and the proposed mechanism. It must be reemphasized that these calculations are only intended to give a relative difference between ions of two different cross sectional areas. A different set of experimental conditions will change the calculated values of ion velocity and kinetic energy. 


\section{Conclusion}

In these experiments, two different conformational forms of proteins are injected into the mass spectrometer: a highly charged, open form, and a less charged, folded form. These two forms have ditferent collisional cross-sections and can be separated on this basis. The more open (higher charge) form has a greater initial velocity but a larger cross section. Its correspondingly higher collision frequency results in its being slowed down more than the more folded form upon collisions with a target gas. At appropriately high target gas pressures, the open form is unable to exit the collision cell, that is, there is not enough translational energy left after collisions, resulting in preferential transmission of the more folded state.

This effect can be reversed by changing the potential on the third quadrupole (mass analysis quadrupole) to a more negative value. Extraction of ions from the collision cell leads to reappearance of the higher charge state ions. Selection for the more folded, lower charge state can be seen in the absence of added collision gas by simply increasing the potential on the third quadrupole. The effect is the same, only less dramatic due to a reduced number of collisions.

Altering the $\mathrm{pH}$ in the protein solutions prior to injection into the mass spectrometer is an alternative way of achieving some selection of conformational state. At low $\mathrm{pH}$ values, the protein exists primarily in a "denatured" open form which exists in the gas phase as a highly charged ion. Addition of collision gas in this case results primarily in the loss of this high charge state distribution, with very low abundances of the lower charge state distribution being observed. Note that the different charge state ions possess different initial kinetic energies. The higher charge state ions have higher kinetic energies. However, these ions also experience more collisions due to their correspondingly larger cross sectional areas and, as a result, are expected to experience more dramatic losses in kinetic energy, in accordance with experimental observations. High solution phase $\mathrm{pH}$ values reveal primarily the low charge state conformer corresponding to a smaller, lightly folded state. This conformer is not as susceptible to collisional energy loss and a very slight loss in ion intensity is observed upon addition of collision gas. The native form of the protein is therefore less subject to collisional removal and it might be possible to purify ion beams of denatured protein by using this method. This would allow subsequent ion-molecule relations to be performed with greater specificity. The parallels between this experiment and ion mobility experiments in which ions are separated in time on the basis of elastic collisions is worth noting. It suggests that ion mobility experiments on bimolecules might be possible by adding appropriate timing circuitry [35] to a standard triple quadrupole mass spectrometer equipped with an electrospray source.

\section{Acknowledgments}

This work was supported by the National Science Foundation (CHE92-23791). John Syka, of Finnigan MAT, is acknowledged for valuable discussions of quadrupole theory. Don Riederer and Steve Hoke are recognized for helpful discussions. K. A. Cox acknowledges an ACS Analytical Fellowship supported by Procter and Gamble.

\section{References}

1. Covey, T. R,; Douglas, D. J. I. Am. Soc. Mass Spectrom. 1993, 4,616 .

2. Feng, R.; Konishi, Y. Presented at the 41st ASMS Conference on Mass Spectrometry and Allied Topics; San Francisco, CA, 1993, ThP 200.

3. (a) Fenn, J. B.; Mann, M.; Meng, C. K.; Wong, S. E.; Whitehouse, C. M. Mass Spectrom. Rev. 1990, 9, 37. (b) Fenn, J. B.; Mann, M.; Meng, C. K.; Wong, S. F.; Whitehouse, C. M.: Science 1989, 246, 64

4. (a) Smith, R. D.; Loo, J. A.; Edmonds, C. G.; Barinaga, C. J.; Udseth, H. R. Anal. Chem. 62, 882 (1990). (b) Smith, R. D.; Loo, J.A; Ogorzalek Loo, R. R.; Busman, M.; Udseth, H. R. Mass Spectrom. Rev. 1991, 10, 359.

5. Mann, M. Org. Mass Spectrom. 1990, 25, 575.

6. Iribarne, J. V.; Thomson, B. A. I. Chem. Ptys. 1976, 64, 2287.

7. Wong, S. F.; Meng, C.K.; Fenn, J. B. J. Phys. Chem. 1988, 92, 546.

8. Sakairi, M.; Yergey, A. L.; Sue, K.W.M.; LeBlanc, I.C.Y.; Guevremont, R.; Berman, S.S. Antal. Chem. 1991, 63, 1488.

9. Loo, J. A.; Udseth, H. R.; Smith, R. D. Anal. Biochem. 1989, 179,404

10. Chowdhury, S.K,; Chait, B.T. Biochem. and Biophys. Res. Commtun. 1990, $173,927$.

11. Ikonomou, M.G.; Kebarle, P. Int. I. Mass Spectrom. Ion Processes 1992, 117, 283.

12. McLuckey, S. A.; Van Berkel, G. J.; Glish, G. L. J. Am. Chem. Soc. 1990, 112, 4668.

13. Loo, R.R.; Loo, J. A.; Udseth, H. R.; Fulton, J. L; Smith, R. D. Rapid Commun. Mass Spectrom. 1992, 6, 159.

14. Rockwood, A. L.; Busman, M; Smith, R.D. Int. J. Mass Spectrom. Ion Processes 1991, 91.

15. Smith, R. D.; Loo, J. A.; Barinaga, C. J.; Edmonds, C.G.; Udseth, H. R. J. Am. Soc. Mass Spectrom. 1990, 1, 53.

16. Smith, R.D.; Wahl, K. J. L.; Winger, B.E; Loo, J. A. Org. Mass Spestrom. 1992, 27, 811.

17. Chowdhury, S.K.; Katta, V.; Chait, B. T. I. Am. Chem. Soc. 1990, 112, 9012

18. Loo, J. A.; Loo, R. R.O.; Udseth, H. R.; Edmonds, C. G.; Smith, R. D. Rapid Commun. Mass Spectrom. 1991, 5, 101.

19. Mirza, U. A.; Cohen, S. L.; Chait, B. T. Anal. Chem. 1993, 65 , 1.

20. LeBlanc, J. C. Y.; Beuchemin, D,; Siu, K. W.M.; Guevremont, R; Berman, S.S. Org. Mass Spectrom. 1991, 26, 831.

21. Rockwood, A.L.; Busman, M.; Udseth, H. R,; Smith, R.D. Rapid. Commun. Mass Spectrom. 1991, 5, 582.

22. (a) Katta, V.; Chait, B.T. Rapid Commun. Mass Spectrom. 5, 214 (1991). (b) Winger, B.E.; Light-Wahl, K. J.; Rockwood, A. L.; Smith, R.D. J. Am. Chem. Soc. 1992, 114, 5897. (c) Brown, C.; Camilleri, P.; Haskins, N.J.; Saunders, M. J. Chem. Soc. Chem. Commun., 1992, 761. (d) Suckau, D.; Shi, Y; Beu, S.C.; Senko, M.W.; Quinn, J.P.; Wampler, F.M.; McLafferty, F. W. Proc. Natl. Acad. Sci. USA 1993, 90, 790.

23. Morris, H. R.; Pucci, P; Panico, M.; Marino, G. Biochem. J. 1990, 268, 803.

24. McLuckey, S. A.; Glish, G. L.; Van Berkel, G.J. Anal. Chem. 1991, 63, 1971. 
25. Loo, J. A.; Edmonds, C. G.; Udseth, H. R.; Smith, R. D. Anal. Chim. Acta 1990, 241, 167.

26. Smith, R. D.; Barinaga, C.J. Rapid Commun. Mass Spectrom. $1990,4,54$

27. Smith, R. D.; Barinaga, C. J.; Udseth, H.R. J. Phys. Chem. 1989, 93, 5019.

28. Loo, J.A.; Udseth, H. R.; Smith, R.D. Rapid Commun. Mass Spectrom. 1988, 2, 207.

29. Feng, R.; Konishi, Y. Presented at the 39th ASMS Conference on Mass Spectrometry and Allied Topics, Nashville, TN, $1432,1991$.
30. McDaniel, E. W. Collision Phenomena in lonized Gases, John Wiley: New York (1964).

31. Hill, Jr., H. H.; Siems, W. F.; St. Louis, R. H.; McMinn, D. G. Anal. Chem. 1990, 62, 1201A.

32. von Helden, G.; Kemper, P. R.; Gotts, N. G.; Bowers, M.T. Science 1993, 259, 1300

33. Hunter, J.; Fye, J.; Jarrold, M. F. J. Phys. Chem. 1993, 97 , 3460.

34. Macfarlane, R.D. Acc. Chem. Res. 1982, 15, 268.

35. Ranasinghe, A.; Cooks, R.G.; Sethi, S. K. Org. Mass Spectrom. $1992,27,77$. 